\title{
Down syndrome associated childhood myeloid leukemia with yet unreported acquired chromosomal abnormalities and a new potential adverse marker: dup(1)(q25q44)
}

\author{
Faten Moassass', Abdulsamad Wafa' ${ }^{1}$, Thomas Liehr ${ }^{2}$, Ayman Al-Ablog ${ }^{1}$ and Walid AL Achkar ${ }^{1 *}$
}

\begin{abstract}
Background: Children with constitutional trisomy 21, i.e. Down syndrome (DS, OMIM \#190685) have a 10 to 20-fold increased risk for a hematopoietic malignancy. They may suffer from acute lymphoblastic leukemia or acute myeloid leukemia (AML). AML referred to as myeloid leukemia of Down syndrome (ML-DS) is observed especially after birth at an early gestational age and characterized by enhanced white blood cell count, failure of spontaneous remission, liver fibrosis or liver dysfunction, and is significantly associated with early death. There are only few studies yet focusing on the clonal cytogenetic changes during evolution of ML-DS.

Case presentation: In a 1.4-year-old boy with DS an immunophenotype consistent with AML-M1 according to French-American-British (FAB) classification was diagnoses. Cytogenetic and molecular cytogenetic analyses revealed, besides constitutional free trisomy 21 , an unbalanced translocation as $\operatorname{der}(16) t(1 ; 16)(q 25.3 ; q 24)$, plus a balanced translocation $\mathrm{t}(3 ; 20)(\mathrm{q} 25 ; \mathrm{q} 13.1)$. A poor clinical outcome was observed here.

Conclusions: To the best of our knowledge, an ML-DS case associated with identical acquired chromosomal abnormalities was not previously reported. Our findings suggest that especially partial trisomy $1 \mathrm{q} 25$ to $1 \mathrm{q} 44$ may be indicative for a poor prognosis in ML-DS.
\end{abstract}

Keywords: Down syndrome, Trisomy 21, AML, Acquired chromosomal abnormalities (ACAs), Clone evolution, Cytogenetics, Fluorescence in situ hybridization (FISH), Prognostic factors

\section{Background}

Children with trisomy 21 or Down syndrome (DS, OMIM \#190685) have a compared to normal population 10- to 20-fold increased risk for developing an acute leukemia; lymphoblastic as well as myeloid leukemia were reported $[1,2]$. Acute myeloid leukemia- (AML-) affected children develop a unique type of malignancy, referred to as myeloid leukemia of Down Syndrome (ML-DS), which is recognized as a separate entity in the actual World Health Organization (WHO) classification

\footnotetext{
* Correspondence: ascientific@aec.org.sy

${ }^{1}$ Molecular Biology and Biotechnology Department, Human Genetics

Division, Chromosomes Laboratory, Atomic Energy Commission of Syria, P.O.

Box 6091, Damascus, Syria

Full list of author information is available at the end of the article
}

of leukemia [3]. ML-DS is especially found in children born at early gestational age and is characterized by enhanced white blood cell (WBC) count, failure of spontaneous remission, as well as liver fibrosis or liver dysfunction. Also ML-DS is significantly associated with poor outcome and early death [4-6]. ML-DS cases have, according to French-American-British (FAB) classification, in the majority of the cases M7 morphology, thus they are also called acute megakaryoblastic leukemia (AMKL) cases. As most ML-DS cases are young at diagnosis, the disease occurs almost exclusively in children $<5$ years old. A beneficial clinical outcome may occur if treated with reduced intensity chemotherapy protocols without stem cell transplantation [7-9]. 
Even though data on cytogenetics of ML-DS are scarce, it is known that the karyotypic patterns of this entity are different from those observed in AML of children without DS, e.g. translocations $\mathrm{t}(8 ; 21), \mathrm{t}(15 ; 17)$, $\mathrm{t}(9 ; 11)$, inversion inv.(16), as well as AMKL associated translocations $t(1 ; 22)$ and $t(1 ; 3)$ are rather typical for ML-DS [10-12]. The most frequent imbalances in ML-DS are duplications in 1q (16\%), or deletions in $7 \mathrm{p}$ (10\%) and/or 16 (7.4\%) [10]. However, the potential clinical impact of these cytogenetic abnormalities is not known, yet. Therefore, the importance of studying and reporting cytogenetic alterations for better classification and risk stratification of ML-DS and non-DS-AML is well recognized $[5,10-14]$. There is especially controversial data on the impact of acquired chromosomal abnormalities (ACAs) in ML-DS (see $[4,14]$ versus $[5,11]$ ).

Here, we describe a typical ML-DS case with two yet unreported ACAs involving chromosomes 1 and 16 as well as 3 and 20, obviously associated with a poor prognosis.

\section{Case presentation}

A 1.4-year-old boy with DS without familial medical history of malignancy presented with 10 days consisting flu and fever, being pallor and unconscious. This patient was the fifth child of healthy, unrelated parents. The mother and the father were at birth of the child, 42 and 54 years old, respectively. Also there was no infection in the pregnant woman during the pregnancy.

At diagnosis the small boy was found to have septicemia, acidosis, dehydration, and lung crackles. Physical examination and ultrasound showed hepatomegaly. His hematological parameters revealed low hemoglobin level (Hgb) $(4 \mathrm{~g} / \mathrm{dl})$, low platelet count $\left(47 \times 10^{9} / \mathrm{l}\right)$, and elevated WBC count. Biochemistry determined urea of $118 \mathrm{mg} / \mathrm{dl}$ (normal value up to $40 \mathrm{mg} / \mathrm{dl}$ ) but normal creatinine levels $(0.1 \mathrm{mg} / \mathrm{dl})$. Thus, he was diagnosed as ML-DS patient. The patient received blood transfusion repeatedly, stayed in the hospital for 1 week, and then was transferred to hematological malignancy hospital to confirm diagnosis and treatment. Peripheral blood cell analyses revealed a WBC count of $59.08 \times 10^{9} / 1(18.8 \%$ neutrophils, $47.2 \%$ lymphocytes, $0.1 \%$ eosinophiles, $29.6 \%$ monocytes and $4.3 \%$ basophiles), red blood cells count of $4.93 \times 10^{6} / \mathrm{mm}^{3}$, Hgb level of $11.2 \mathrm{~g} / \mathrm{dl}$, and platelet count of $24 \times 10^{9} / 1$. Blasts in bone marrow aspiration were present in $32 \%$ of analyzed cells. The patient had not received any chemotherapy treatment and died unfortunately died 9 days after diagnosis from the disease due to respiratory arrest, and before cytogenetic and flowcytometric results were available. His mother agreed with scientific evaluation of the case and the study was approved by the ethical committee of the Atomic Energy Commission, Damascus, Syria.
GTG-banding on peripheral blood sample revealed a karyotype of $47, \mathrm{XY}, \mathrm{t}(1 ; 16)(? ; ?), \mathrm{t}(3 ; 20)(? ; ?),+21 \mathrm{c}[17] / 47, \mathrm{X}$ $\mathrm{Y},+21 \mathrm{c}[3]$ (Fig. 1). Further studies were performed by molecular cytogenetics (Fig. 2). Dual-color-FISH (DFISH) using specific WCP probes for chromosomes \#1, $\# 3$, \#16, and \#20 confirmed that no other chromosomes were involved besides \#1 and \#16 in an imbalanced plus $\# 3$ and \#20 in a balanced translocation (data not shown). aMCB, using probes for chromosomes \#1, \#3, \#16, and \#20 (Fig. 2) revealed the following final karyotype:

$$
\begin{aligned}
& \text { 47,XY,der(16)t(1;16)(q25.3;q24),t(3;20)(q25;q13.1), } \\
& +21 \mathrm{c}[17] / 47, \mathrm{XY},+21 \mathrm{c}[3]
\end{aligned}
$$

Immunophenotyping of peripheral blood specimen characterized this case as AML-M1 according to FAB classification. The blast cell population (32\% of leukocytes) was positive for CD45 ${ }^{\mathrm{dim}}, \mathrm{CD} 7, \mathrm{CD} 13 \mathrm{dim}, \mathrm{CD} 33$, HLA-DR, CD38, and CD117 and negative for CD64, CD34, CD10, CD15, CD11b and CD14.

\section{Discussion and conclusions}

The natural history of leukemia in children with DS suggests that trisomy 21 directly contributes to the malignant transformation of hematopoietic cells. Approximately $15 \%$ of pediatric AML cases occur in DS children. Thus, ML-DS contribute more than $90 \%$ of the most common FAB subtype of DS AML patients and at the same time the majority of cases are diagnosed under the age of 4 years [15-17]. Zipursky et al. [9] have estimated that DS children have a 500-fold increased risk of developing ML-DS compared with non-DS children, highlighting the unique relationship between trisomy 21 , leukemogenesis, and a specific leukemia phenotype. Other AML FAB subtypes have also been described in ML-DS including M0, M1/M2, and M6, but less frequently [15-17].

The cytogenetic profiles of ML-DS cases differ significantly from non-DS patients with AML [16, 18, 19]. ML-DS children show more frequently acquired trisomies of chromsomes 8,11 , and $19, \operatorname{dup}(1 \mathrm{p}), \operatorname{del}(6 \mathrm{q})$, $\operatorname{del}(7 p), \operatorname{dup}(7 q)$, and $\operatorname{del}(16 q)$ [10]. Typically, the favorable translocations associated with non-DS AML [e.g., $\mathrm{t}(8 ; 21) ; \mathrm{t}(15 ; 17) ; \operatorname{inv}(16), 11 \mathrm{q} 23$ rearrangements] are rarely seen in ML-DS patients [10]. For ML-DS children older than 4 years cytogenetic features, molecular biology findings and response to therapy significantly diverge from younger patients, and are similar to the ones found in non-DS patients with AML [17]. However, recently de Souza et al. [20] reported a new ML-DS case associated with new acquired ACAs and they suggested those were clearly associated with the disease-progress and associated with an adverse risk. The case presented here share some feature with that of de Souza et al. [20] 

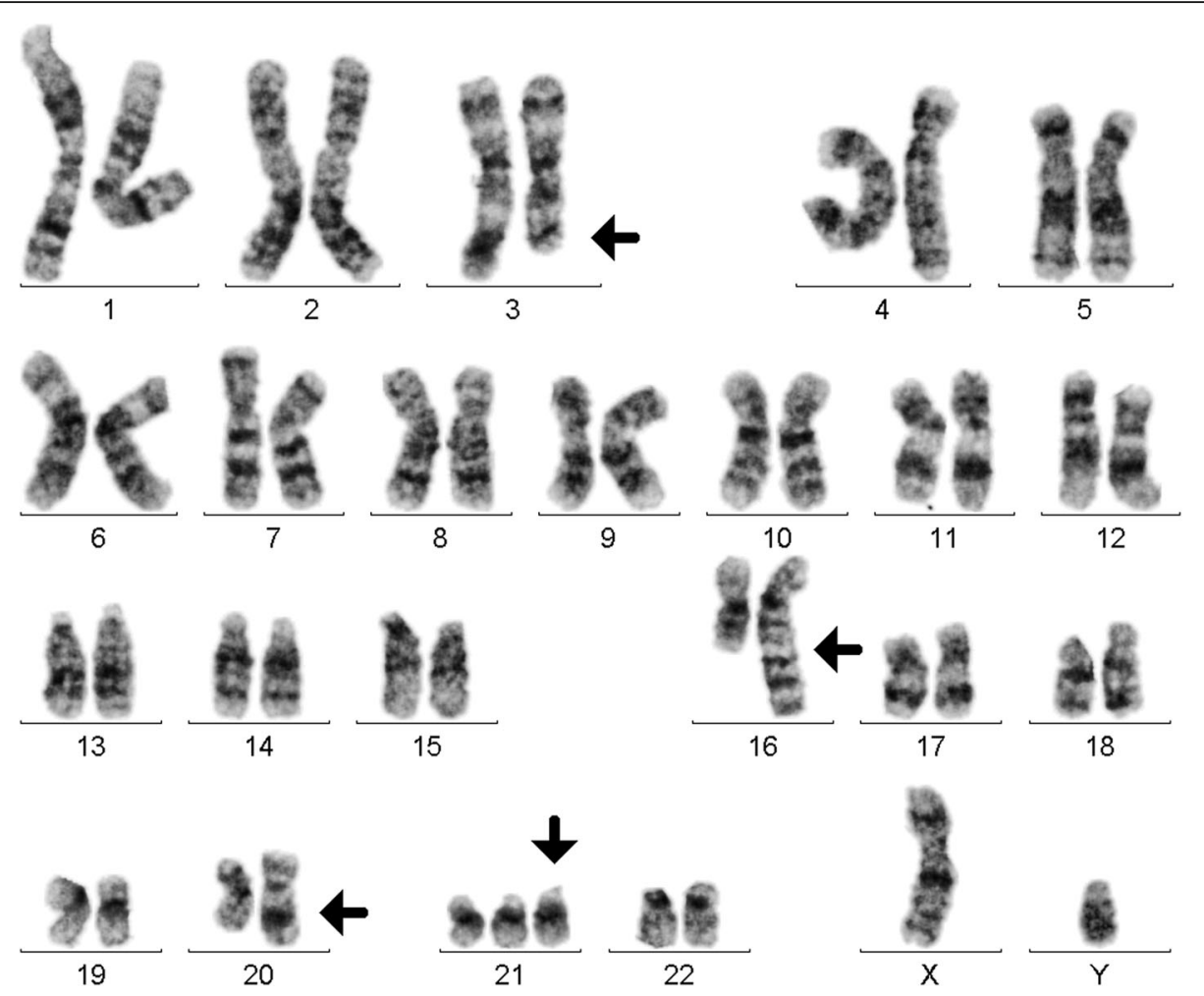

Fig. 1 GTG-banding revealed an unbalanced translocation t(1;16)(q25.3;q24) and balanced translocation t(3;20)(q25;q13.1) in 17/20 metaphases. All derivative chromosomes are marked and highlighted by arrow heads
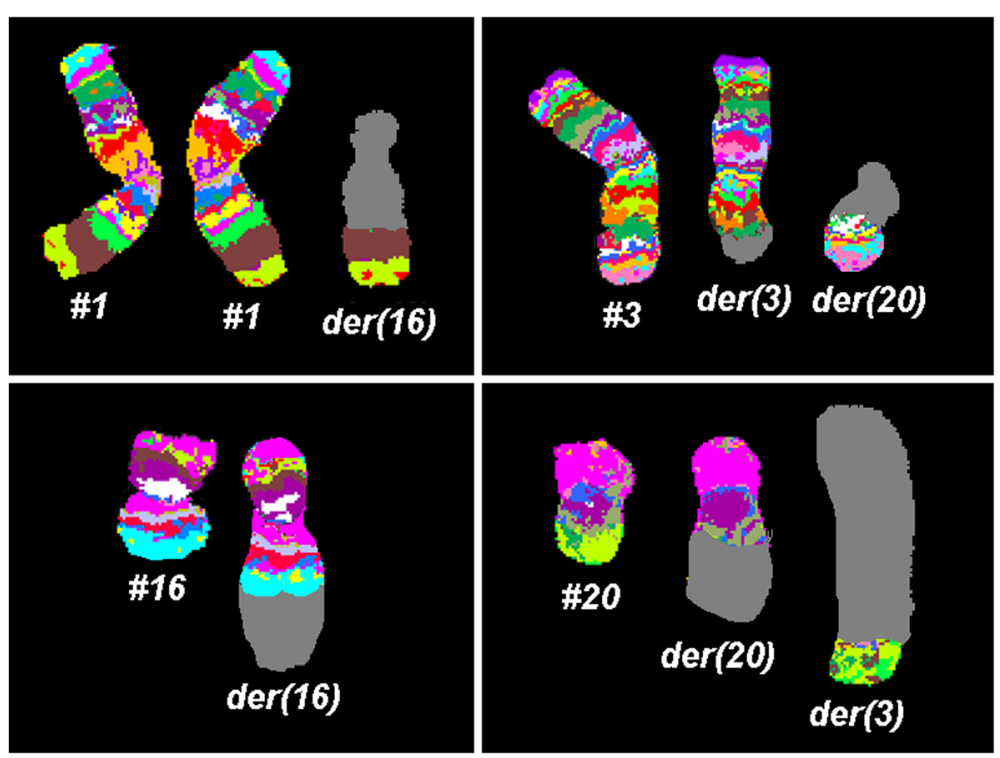

Fig. 2 Karyotype and chromosomal aberrations were confirmed using molecular cytogenetic approaches. aMCB results are shown. The normal chromosomes (\#) are depicted on the left side of each image and the derivative of the other chromosomes on the right side of normal chromosomes. The unstained regions when suing chromosome-specific aMCB-probesets on the derivative chromosomes are shown in gray. Abbreviations: \# = chromosome; der $=$ derivative chromosome 
such as involvement of chromosomes 1 and 3 was and a poor outcome. Furthermore, chromosomal bands such as $1 \mathrm{q} 25,3 \mathrm{q} 25,16 \mathrm{q} 24$, and $20 \mathrm{q} 13$ are involved in chromosomal rearrangements frequently [21]. Moreover, translocations or inversions involving 3q21 and $3 q 26$ are associated with a high-risk in AML, and these patients usually present with a poor prognosis [17]. However, in our case observed specific translocations $\operatorname{der}(16) \mathrm{t}(1 ; 16)(\mathrm{q} 25.3 ; \mathrm{q} 24)$ and $\mathrm{t}(3 ; 20)(\mathrm{q} 25 ; \mathrm{q} 13.1)$ has never been reported as ACAs in ML-DS or AML cases to date [21].

Several studies have suggested that mutations in the hematopoietic zinc-finger transcription factor gene GATA-1 (a transcription factor that regulates the differentiation of megakaryocyte and erythrocyte precursors), could be an initiating event in DS leukemogenesis [22, 23]. Besides the involvement of GATA-1 and trisomy 21 is strongly associated with leukemogenesis [20]. Cytogenetic analyses revealed other acquired recurrent abnormalities associated with gain of chromosome 21 . Forestier et al. [10] analyzed 189 ML-DS cases and they confirmed a distinct entity, originating from other genetic pathways than non-DS patients with AML.

Partial trisomy of chromosome 1q is commonly observed in infants with ML-DS and AMKL, which is most often resulting from an unbalanced translocation, like in the present case, or a simple duplication [24]. The long arm of chromosome 1 accommodates genes involved in the control of normal myeloid cell kinetics. Several interesting genes map in this region 1q, including IL6RA and $B C L 2$-related are located at $1 \mathrm{q} 21, M N D A$ (1q22), CENPR (1q32-q41), and TP53BP2 (1q42.1 q42.2) [25].

For the chromosome 16 related imbalance two genes might specifically be considered: (i) Interferon regulatory factor 8 (IRF8) also known as interferon consensus sequence-binding protein located at 16q24.1, codes for a transcription factor, which plays a critical role in the regulation of lineage commitment and myeloid cell maturation including the checkpoint for a common myeloid progenitor to differentiate into a monocyte precursor cell [26]. (ii) The human FOXF1 gene located at 16q24.1, previously denominated Forkhead Related ACtivator-1, encodes a homologue of the mouse forkhead box-F1 (Foxf1) transcription factor [27]. Gene knockout studies have shown that the function of mouse Foxf1 is indispensable for organ morphogenesis, including the lung, liver, gallbladder, esophagus, and trachea [28]. Despite the largely unknown role of FOXF1 in cancer, several lines of evidence have linked human FOXF1 function to tumorigenesis [29]. Recently, it was suggested that FOXF1 may play a dual role in tumorigenesis as an oncogene or a tumor suppressor gene depending on tissue cell types and disease stages [30].
As shortly discussed above, age has been recognized as a prognostic factor in ML-DS [31]. In fact, it has been proposed that DS children who present over 4 years of age are suffering from 'normal sporadic AML' occurring in a child with DS, rather than from 'true' ML-DS [32]. In addition, ML-DS patients with a history of transient myeloproliferative disease have a significantly better outcome than children with ML-DS without documented transient myeloproliferative disease [5]. Blink et al. [11] demonstrated that age $\geq 3$ years and high WBC count $\left(>20 \times 10^{9}\right)$ are correlated with poor outcome (eventfree survival) in ML-DS. These variables are also known from non-DS pediatric AML studies, in which older age and high WBC predict for poor outcome [33].

According to the literature the here observed partial monosomy 16q24 to 16qter has no clear impact on prognosis, and the meaning of the balanced translocation $t(3 ; 20)$ (q25;q13.1) needs to be delineated by further case studies. However, the present case of ML-DS may have an adverse outcome due to the partial trisomy $1 \mathrm{q} 25.3$ to 1qter, as also supported at least by one further similar case [20] and the known adverse effects of distal partial trisomy 1q in other malignancies [32].

\section{Material and methods}

\section{Cytogenetics and molecular cytogenetics}

Chromosomal analysis on peripheral blood sample using GTG-banding according to standard procedures [34] was performed prior blood transfusions. A minimum of 20 metaphase cells was analyzed. The karyotype was described according to the International System for Human Cytogenetic Nomenclature (ISCN 2016) [35].

Fluorescence in situ hybridization (FISH) using whole chromosome painting (WCP) probes for chromosomes 1, 3, 16, and 20 (MetaSystems, Altlussheim, Germany) was done according to manufacturer's instructions [34]. Array-proven multicolor banding (aMCB) probes sets based on microdissection derived region-specific libraries for chromosomes 1, 3, 16, and 20 were hybridized and evaluated as previously reported [36]. A minimum of 10 metaphase spreads were analyzed, each, using a fluorescence microscope (AxioImager.Z1 mot, Carl Zeiss Ltd., Hertfordshire, UK) equipped with appropriate filter sets to discriminate between a maximum of five fluorochromes plus the counterstain DAPI $\left(4^{\prime}, 6\right.$ diamino-2-phenylindole). Image capture and processing were performed using an ISIS imaging system (MetaSystems).

\section{Flow cytometric immunophenotype}

Immunophenotyping was performed using a general panel of fluorescent antibodies against the following antigens typical for different cell lineages and cell types: CD1a, CD2, CD3, CD4, CD5, CD8, CD10, CD11b, 
CD11c, CD13, CD14, CD15, CD16, CD19, CD20, CD22, CD23, CD32, CD33, CD34, CD38, CD41a, CD45, CD56, CD57, CD64, CD103, CD117, CD123, CD138, CD209, $\mathrm{CD} 235 \mathrm{a}$ and CD243; in addition antibodies to Kappa and Lambda light Chains, IgD, sIgM, and HLADr were tested. All antibodies were purchased from BD Biosciences. Samples were analyzed on a BD FACSCalibur ${ }^{\mathrm{Tm}}$ flow cytometer. Autofluorescence, viability, and isotype controls were included. Flow cytometric data acquisition and analysis were conducted by BD Cellquest ${ }^{\mathrm{Tm}}$ Pro software.

\begin{abstract}
Abbreviations
ACAs: Additional cytogenetic abnormalities; aMCB: Array-proven high-resolution multicolor banding; AMKL: Acute megakaryoblastic leukemia; AML: Acute myeloid leukemia; DAPI: 4',6- diamino-2-phenylindole; D-FISH: Dual-color-fluorescence in situ hybridization; DS: Down syndrome; FAB: French-American-British classification; FISH: Fluorescence in situ hybridization; Foxf1: Mouse forkhead box-F1 transcription factor; Hgb: Hemoglobin level; IRF8: Interferon regulatory factor 8 gene; ISCN 2016: International System for Human Cytogenetic Nomenclature; ML-DS: Myeloid leukemia of Down syndrome; WBC: White blood cell count; WCP: Whole chromosome paint probes; WHO: World Health Organization classification
\end{abstract}

\section{Acknowledgements}

We thank Prof. I. Othman, the Director General of Atomic Energy Commission of SYRIA (AECS) and Dr. N. Mirali, Head of Molecular Biology and Biotechnology Department for their support.

\section{Funding}

n.a.

\section{Availability of data and materials}

The data sets supporting the conclusions of this article are included within the article.

\section{Authors' contributions}

FM, AW, AA and WA performed banding cytogenetics and provided the clinical data; FM, AW and TL performed the molecular cytogenetic analyses. AW and TL drafted the paper and all authors worked on the final version of the paper. All authors read and approved the final manuscript.

\section{Ethics approval and consent to participate}

This study was approved by approved by by the Bio-Safety \& Bioethics committee of the Institutional Ethical Committee of AECS.

\section{Consent for publication}

Written informed consent was obtained from the patient's mother for publication of this case report and accompanying images. A copy of the written consent is available for review by the Editor-in-Chief of this journal.

\section{Competing interests}

The authors declare that they have no competing interests.

\section{Publisher's Note}

Springer Nature remains neutral with regard to jurisdictional claims in published maps and institutional affiliations.

\section{Author details}

'Molecular Biology and Biotechnology Department, Human Genetics Division, Chromosomes Laboratory, Atomic Energy Commission of Syria, P.O. Box 6091, Damascus, Syria. ${ }^{2}$ Jena University Hospital, Institute of Human Genetics, Am Klinikum 1, 07747 Jena, Germany.
Received: 10 January 2018 Accepted: 7 March 2018

Published online: 13 March 2018

\section{References}

1. Rabin KR, Whitlock JA. Malignancy in children with trisomy 21. Oncologist. 2009:14:164-73.

2. Zwaan MC, Reinhardt D, Hitzler J, Vyas P. Acute leukemias in children with Down syndrome. Pediatr Clin N Am. 2008;55:53-70.

3. Hasle H, Niemeyer CM, Chessells JM, Baumann I, Bennett JM, Kerndrup G Head DR. A pediatric approach to the WHO classification of myelodysplastic and myeloproliferative diseases. Leukemia. 2003;17:277-82.

4. Massey GV, Zipursky A, Chang MN, Doyle JJ, Nasim S, Taub JW, Ravindranath Y, Dahl G, Weinstein HJ, Children's Oncology Group (COG). A prospectivestudy of the natural history of transientleukemia (TL) in neonates with Down syndrome (DS): Children's Oncology Group (COG) study POG9481. Blood. 2006;107:4606-13.

5. Klusmann JH, Creutzig U, Zimmermann M, Dworzak M, Jorch N, Langebrake C, Pekrun A, Macakova-Reinhardt K, Reinhardt D. Treatment and prognostic impact of transient leukemiain neonates with Down syndrome. Blood. 2008;111:2991-8.

6. Muramatsu H, Kato K, Watanabe N, Matsumoto K, Nakamura T, Horikoshi Y, Mimaya J, Suzuki C, Hayakawa M, Kojima S. Riskfactors for early death in neonates with Down syndrome and transient leukaemia. Br J Haematol. 2008;142:610-5.

7. Creutzig U, Reinhardt D, Diekamp S, Dworzak M, Stary J, Zimmermann M. AML patients with Down syndrome have a high cure rate with AML-BFM therapy with reduced dose intensity. Leukemia. 2005:19:1355-60.

8. Rao A, Hills RK, Stiller C, Gibson BE, de Graaf SS, Hann IM, O'Marcaigh A, Wheatley K, Webb DK. Treatment for myeloid leukaemia of Down syndrome: population-based experience in the UK and results from the Medical Research Council AML 10 and AML 12 trials. Br J Haematol. 2006;132:576-83.

9. Zipursky A, Thorner P, De Harven E, Christensen H, Doyle J. Myelodysplasia and acute megakaryoblastic leukemia in Down's syndrome. Leuk Res. 1994; 18:163-71.

10. Forestier E, Izraeli S, Beverloo B, Haas O, Pession A, Michalova K, Stark B, Harrison CJ, Teigler-Schlegel A, Johansson B. Cytogenetic features of acute lymphoblastic and myeloid leukemias in pediatric patients with Down syndrome: an iBFM-SG study. Blood. 2008;111:1575-83.

11. Blink $M$, Zimmermann $M$, von Neuhoff $C$, Reinhardt $D$, de Haas $V$, Hasle $H$, O'Brien MM, Stark B, Tandonnet J, Pession A, Tousovska K, Cheuk DK, Kudo K, Taga T, Rubnitz JE, Haltrich I, Balwierz W, Pieters R, Johansson B, van den Heuvel-Eibrink MM, Zwaan CM. Normal karyotype is a poor prognostic factor in myeloid leukemia of Down syndrome: a retrospective, international study. Haematologica. 2014;99:299-307.

12. Bhatnagar N, Nizery L, Tunstall O, Vyas P, Roberts I. Transient abnormal myelopoiesis and AML in Down syndrome: an update. Curr Hematol Malig Rep. 2016;11:333-41.

13. Arber DA, Orazi A, Hasserjian R, Thiele J, Borowitz MJ, Le Beau MM, Bloomfield CD, Cazzola M, Vardiman JW. The 2016 revision to the World Health Organization classification of myeloid neoplasms and acute leukemia. Blood. 2016:127:2391-405.

14. Picos Cárdenas VJ, Meza Espinoza JP, Garibaldi Covarrubias RF, Barajas Torres RL, González García JR. Transient myeloproliferative disorder progression and acquired chromosomal abnormalites in children with Down syndrome. Pediatr Blood Cancer. 2012;59:962-3.

15. Ravindranath Y, Yeager AM, Chang MN, Steuber CP, Krischer J, Graham-Pole J, Carroll A, Inoue S, Camitta B, Weinstein HJ. Autologous bone marrow transplantation versus intensive consolidation chemotherapy for acute myeloid leukemia in childhood. Pediatric Oncology Group. N Engl J Med. 1996:334:1428-34

16. Lange BJ, Kobrinsky N, Barnard DR, Arthur DC, Buckley JD, Howells WB, Gold S, Sanders J, Neudorf S, Smith FO, Woods WG. Distinctive demography, biology, and outcome of acute myeloid leukemia and myelodysplastic syndrome in children with Down syndrome: children's Cancer Group Studies 2861 and 2891. Blood. 1998:91:608-15.

17. Gamis AS, Woods WG, Alonzo TA, Buxton A, Lange B, Barnard DR, Gold S, Smith FO. Increased age at diagnosis has a significantly negative effect on outcome in children with Down syndrome and acute myeloid leukemia: a report from the Children's Cancer Group Study 2891. J Clin Oncol. 2003:21:3415-22.

18. Zeller B, Gustafsson G, Forestier E, Abrahamsson J, Clausen N, Heldrup J, Hovi L, Jonmundsson G, Lie SO, Glomstein A, Hasle H, Nordic Society of Paediatric Haematology and Oncology (NOPHO). Acute leukaemia in 
children with Down syndrome: a population-based Nordic study. $\mathrm{Br} J$ Haematol. 2005;128:797-804.

19. Creutzig U, Ritter J, Vormoor J, Ludwig WD, Niemeyer C, Reinisch I, Stollmann-Gibbels B, Zimmermann M, Harbott J. Myelodysplasia and acute myelogenous leukemia in Down's syndrome. A report of 40 children of the AML-BFM Study Group. Leukemia. 1996;10:1677-86.

20. de Souza DC, de Figueiredo AF, Ney Garcia DR, da Costa ES, Othman MAK, Liehr T, Abdelhay E, Silva MLM, de Souza Fernandez T. A unique set of complex chromosomal abnormalities in an infant with myeloid leukemia associated with Down syndrome. Mol Cytogenet. 2017;10:35.

21. Mitelman F, Johansson B, Mertens F, editors: Mitelman database of chromosome aberrations and gene fusions in cancer (2017). http://cgap.nci. nih.gov/Chromosomes/Mitelman. Accessed 18 Sept 2017.

22. Gurbuxani S, Vyas P, Crispino JD. Recent insights into the mechanisms of myeloid leukemogenesis in Down syndrome. Blood. 2004;103:399-406.

23. Hitzler JK, Zipursky A. Origins of leukaemia in children with Down syndrome. Nat Rev Cancer. 2005;5:11-20.

24. Silva ML, Pombo-de-Oliveira MS, Raimondi SC, Mkrtchyan H, Abdelhay E, de Figueiredo AF, de Souza MT, Garcia DR, de Ventura EM, de Sousa AM, Liehr T. Unbalanced chromosome 1 abnormalities leadingto partial trisomy $1 \mathrm{q}$ in four infants with Downsyndrome and acute megakaryocytic leukemia. Mol Cytogenet. 2009;2:7.

25. Cho HS, Kim M, Hyun MS. Triplication of $1 \mathrm{q}$ in a patient with myelodysplastic syndrome. Korean J Hematol. 2006;41:56-60.

26. Weisz A, Marx P, Sharf R, Appella E, Driggers PH, Ozato K, Levi BZ. Human interferon consensus sequence binding protein is a negative regulator of enhancer elements common to interferon-inducible genes. J Biol Chem. 1992;267:25589-96.

27. Hellqvist M, Mahlapuu M, Samuelsson L, Enerback S, Carlsson P. Differential activation of lung-specific genes by two forkhead proteins, FREAC-1 and FREAC-2. J Biol Chem. 1996;271:4482-90.

28. Kalinichenko W, Zhou Y, Bhattacharyya D, Kim W, Shin B, Bambal K, Costa $\mathrm{RH}$. Haploinsufficiency of the mouse Forkhead Box $\mathrm{f1}$ gene causes defects in gall bladder development. J Biol Chem. 2002;277:12369-74.

29. Lo PK, Lee JS, Liang X, Han L, Mori T, Fackler MJ, Sadik H, Argani P, Pandita TK, Sukumar S. Epigenetic inactivation of the potential tumor suppressor gene FOXF1 in breast cancer. Cancer Res. 2010;70:6047-58.

30. Lo PK, Lee JS, Chen H, Reisman D, Berger FG, Sukumar S. Cytoplasmic mislocalization of overexpressed FOXF1 is associated with the malignancy and metastasis of colorectal adenocarcinomas. Exp Mol Pathol. 2013;94:262-9.

31. Sorrell AD, Alonzo TA, Hilden JM, Gerbing RB, Loew TW, Hathaway L, Barnard D, Taub JW, Ravindranath Y, Smith FO, Arceci RJ, Woods WG, Gamis AS. Favorable survival maintained in children who have myeloid leukemia associated with Down syndrome using reduced-dose chemotherapy on Children's Oncology Group trial A2971: a report from the Children's Oncology Group. Cancer. 2012;118:4806-14.

32. Hasle H, Abrahamsson J, Arola M, Karow A, O'Marcaigh A, Reinhardt D, Webb DK, van Wering E, Zeller B, Zwaan CM, Vyas P. Myeloid leukemia in children 4 years or older with Down syndrome often lacks GATA1 mutation and cytogenetics and risk of relapse are more akin to sporadic AML. Leukemia. 2008;22:1428-30.

33. Wechsler J, Greene M, McDevitt MA, Anastasi J, Karp JE, Le Beau MM, Crispino JD. Acquired mutations in GATA1 in the megakaryoblastic leukemia of Down syndrome. Nat Genet. 2002;32:148-52.

34. AL-achkar W, Wafa A, Nweder MS. A complex translocation $t(5 ; 9 ; 22)$ in Philadelphia cells involving the short arm of chromosome 5 in a case of chronic myelogenous leukemia. J Exp Clin Cancer Res. 2007;26:411-5.

35. McGowan-Joran J, Simons A, Schmid MS. ISCN 2016: an international system of human cytogenomic nomenclature. Unionville: S. Karger Publications, Inc; 2016

36. Liehr T, Heller A, Starke H, Rubtsov N, Trifonov V, Mrasek K, Weise A, Kuechler A, Claussen U. Microdissection based high resolution multicolor banding for all 24 human chromosomes. Int J Mol Med. 2002;9:335-9.

\section{Submit your next manuscript to BioMed Central and we will help you at every step:}

- We accept pre-submission inquiries

- Our selector tool helps you to find the most relevant journal

- We provide round the clock customer support

- Convenient online submission

- Thorough peer review

- Inclusion in PubMed and all major indexing services

- Maximum visibility for your research

Submit your manuscript at www.biomedcentral.com/submit
) Biomed Central 